\title{
Synergy Effect of Environmental Factors on the Growth and Toxins Production by Microcystis aeruginosa
}

\author{
Hou Wei, Song Yundi, Lu Nan, Zhang Runjie, Bu Naishun, Miao Bin, He Zhe and Fu Baorong $\dagger$ \\ College of Environmental Science, Liaoning University, Shenyang 110036, P.R. China \\ †Corresponding author: Fu Baorong; 826923232@163.com
}

Nat. Env. \& Poll. Tech.

Website: www.neptjournal.com

Received: 14-03-2020

Revised: 19-04-2020

Accepted: 13-06-2020

\section{Key Words:}

Microcystis aeruginosa

Microcystins

Illumination intensity

Orthogonal analysis

\begin{abstract}
Microcystis is one of the most common algal genera that causes water eutrophication. The effect of water quality on the growth and toxins production of Microcystis has been attracting high research attentions. The relationship of different combinations of temperature, illumination intensity, nitrogen and phosphorus with the growth and toxin production of Microcystis aeruginosa was explored through an orthogonal test. Results showed that illumination intensity influences the growth of Microcystis aeruginosa mostly, followed by temperature, total nitrogen (TN) and total phosphorus (TP). Illumination intensity affects the toxin production of Microcystis aeruginosa most significantly, followed by TP, TN and temperature successively. $200 \mathrm{Lx}$ illumination intensity, $22^{\circ} \mathrm{C}$ temperature, $20 \mathrm{mg} \cdot \mathrm{L}^{-1} \mathrm{TN}$ and 0.6 $\mathrm{mg} \cdot \mathrm{L}^{-1}$ are the optimum toxin production conditions for Microcystis aeruginosa.
\end{abstract}

\section{INTRODUCTION}

Harmful cyanobacterial blooms are one of the most severe problems in freshwater ecosystems. A Survey of the United Nations Environment Programme (UNEP) reported that $30-40 \%$ of lakes and reservoirs in the world are suffering from eutrophication (Ingrid \& Jamie 1999). Microcystis aeruginosa is the most successful bloom-forming organisms in many freshwater ecosystems (Lin et al. 2019). Microcystis is not only the dominant algae in eutrophic water but also toxin-producing algae that can produce Microcystins (MCs) (Puschner et al. 1999, Azevedo et al. 2002). These toxins are harmful to a wide range of organisms (Gilbert 1996, Liu et al. 2006, Tilimanns et al. 2008). Microcystins are a kind of heptad peptide monocyclic compound. Its ring structure is D-Ala-L-X-red- $\beta$-methyl-D-isoaspartate-L-Z-Adda-Disoglutamic acid-N-methyl dehydroalanine. Currently, 75 isomers of MC have been discovered (Van Apeldoorn et al. 2006). MCs are water-soluble and have strong heat resistance, but are difficult to be deposited or adsorbed. In 1998, the World Health Organization (WHO) has determined the base value of MCs in water at $1 \mu \mathrm{g} / \mathrm{L}$ (WHO 1998).

Both existing Chinese and foreign researches on toxin production mechanism of Microcystis mainly focus on genetic and environmental factors (Joung et al. 2011, Jähnichen et al. 2011, Reichwaldt \& Ghadouani 2012). Environmental factors mainly include water temperature, illumination intensity and nutritive salts like nitrogen and phosphorus (Watanabe \& Oishi 1985, Rapala 1988, Oh et al. 2000, Kameyama et al. 2002). However, no agreement on the influence of the environment on toxin production mechanism has been reached yet. Utkilen \& Gjølme (1992) pointed out that illumination may be the only influencing factor of toxin production of Microcystis. Wiedner et al. (2003) cultured Microcystis PCC7806 continuously, finding that the MC content per unit cell has a significant positive correlation with illumination intensity under limited illumination, but turns into a negative one under adequate illumination. Kameyama et al. (2003) conducted batch cultivation of Microcystis viridis NIES102 under different concentrations of nitrogen and phosphorus but didn't find a significant relationship between intracellular MC and nitrogen concentration within the logarithmic growth period. Downing et al. (2005) studied Microcystis PCC7806 and Microcystis UV027, and found that MC concentration per unit cell is related to N/P. Although some studies have involved the effect of illumination, nitrogen and phosphorus content on toxin production mechanism of Microcystis, growth and toxin production of algae have abundant influencing factors and no research has explored the effect degrees of different factors on toxin production mechanism of Microcystis and their combined effect. Hence, it is necessary to study the combined effect of different factors on the growth and toxin production characteristics of algae. 
Based on the effect of a single factor on the growth and toxin production of Microcystis, this paper further explored the combined effect of nitrogen, phosphorus, temperature and illumination by using the $\mathrm{L} 9\left(3^{4}\right)$ orthogonal test.

\section{MATERIALS AND METHODS}

\section{Experimental Chemicals}

Methanol: chromatographically pure ( $\geq 99.9 \%$ ), Sinopharm Chemical Reagent Co., Ltd. Trifluoroacetic acid (TFA): chromatographically pure ( $\geq 99.5 \%)$, Sinopharm Chemical Reagent Co., Ltd. Algal toxin-LR standards: $50 \mu \mathrm{g}$, Biobase Co., Ltd.

\section{Experimental Methods}

1. Algae culture: Testing Microcystis (Microcystis aeruginosa FACHB-315) was bought from Freshwater Algae Culture Collection at the Institute of Hydrobiology (FACHB-collection) and then cultured in an HP 1000GS incubator under artificial climate. The culture medium was improved BG-11. Culture conditions are: $30^{\circ} \mathrm{C}, 1000-1500$ Lux illumination intensity and $14: 10$ illumination/dark. The position of the triangular flask was adjusted randomly and shook 2-3 times regularly every day during the culture.

2. Solution preparation: Monopotassium phosphate solution: $6.8 \mathrm{~g}$ monopotassium phosphate was dissolved in $1,000 \mathrm{~mL}$ ultrapure water.

Phosphate buffered solution: $\mathrm{pH}$ of the monopotassium phosphate solution was adjusted to 3.0 by $20 \%$ phosphoric acid solutions.

Leaching solutions: $10 \mathrm{~mL}$ ultrapure water and $10 \mathrm{~mL}$ $20 \%$ methanol aqueous solutions.

Elution solution: $0.1 \mathrm{~mL}$ TFA (chromatographically pure) was dissolved into $100 \mathrm{~mL}$ methanol (chromatographically pure).

3. Test conditions setting: After the Microcystis had been starved for 3 days, concentrations of nitrogen and phosphorus in the culture medium were adjusted by $\mathrm{Ca}\left(\mathrm{NO}_{3}\right)_{2}$ and $\mathrm{K}_{2} \mathrm{HPO}_{4}$. Culture temperature, illumination intensity and illumination/dark of Microcystis were set by the illumination incubator. The experiments were designed based on the orthogonal test (Table 1).

4. Algae cell density measurement: Blood counting chamber method: water sample was stirred evenly. Three test samples were collected from the upper, middle and bottom layer of the triangular flask respectively to measure the number of algae cells. The mean of three measurements was taken as the final results.
Table 1: Orthogonal experimental scheme.

\begin{tabular}{|lllll|}
\hline Number & $\begin{array}{l}\text { Temperature } \\
\left({ }^{\circ} \mathrm{C}\right)\end{array}$ & $\begin{array}{l}\text { Light } \\
\text { intensity }(\mathrm{Lx})\end{array}$ & $\begin{array}{l}\mathrm{TN} \\
(\mathrm{mg} / \mathrm{L})\end{array}$ & $\begin{array}{l}\mathrm{TP} \\
(\mathrm{mg} / \mathrm{L})\end{array}$ \\
\hline $1 \#$ & 22 & 200 & 20 & 0.4 \\
$2 \#$ & 22 & 500 & 60 & 0.6 \\
$3 \#$ & 22 & 800 & 100 & 1.0 \\
$4 \#$ & 25 & 200 & 60 & 1.0 \\
$5 \#$ & 25 & 500 & 100 & 0.4 \\
$6 \#$ & 25 & 800 & 20 & 0.6 \\
$7 \#$ & 28 & 200 & 100 & 0.6 \\
$8 \#$ & 28 & 500 & 20 & 1.0 \\
$9 \#$ & 28 & 800 & 60 & 0.4 \\
\hline
\end{tabular}

The specific growth rate of Microcystis during the logarithmic phase was analyzed according to its growth curves under different culture conditions (Margarita et al. 2002).

$$
K=\frac{\ln N_{t}-\ln N_{0}}{t-t_{0}}
$$

Where $\mathrm{K}$ is the relative growth rate of cells, t0 means the initial time of the logarithmic phase, $\mathrm{N}_{0}$ is the initial concentration of the logarithmic phase, and $\mathrm{N}_{\mathrm{t}}$ is the algae concentration at time $t$.

5. Absorbance value of Microcystis: Before the test, some Microcystis solution at stable phase was taken and scanned by ultraviolet spectrophotometer under 200-800 nm wavelength, determining that $600-700 \mathrm{~nm}$ is the optimum absorption wavelength. The absorbance value of Microcystis solution under 600-700 nm was tested every other day.

6. Determination of MCs: $80 \mathrm{~mL}$ Microcystis solution was taken and extracted by microwave digestion/extraction instrument (Italy MILESTONE) for 10 min under $100^{\circ} \mathrm{C}$. The extract was then filtered by $0.45 \mu \mathrm{m}$ fibre filter membrane to collect Microcystis solution.

Activation of $\mathrm{C} 18$ solid-phase extraction column (Bona SPE500mg/3cc): $10 \mathrm{~mL}$ methanol was injected into the extraction column activated by $10 \mathrm{~mL}$ water when the methyl alcohol level reached the upper screen of the extraction column.

The collected Microcystis solution was injected into the activated solid-phase column for enrichment. The effluent was reinjected into the column again for secondary enrichment.

After sample enrichment, the $\mathrm{C} 18$ solid-phase extraction column was rinsed by the leaching solution $(10 \mathrm{~mL}$ pure water and $10 \mathrm{~mL} 20 \%$ methanol solution).

MCs in the column was eluted with $10 \mathrm{~mL}$ elution solution. The effluent was collected. 
The effluent was decompressed and steamed to dry by a rotary evaporator (Shanghai HongjiRe-52cs). Add $0.5 \mathrm{~mL}$ $50 \%$ methanol solution until the effluent was completely dissolved. The $2 \mathrm{~mL}$ effluent was used to test.

Detection conditions of HPLC (Varian LC-210): mobile phase: methanol $(\mathrm{V})$ : phosphate buffered solution $(\mathrm{V})=$ 57:43; flow rate: $1 \mathrm{~mL} / \mathrm{min}$; detection wavelength: 238 nm. $20 \mathrm{uL}$ sample was injected. Three parallel tests were conducted.

After finishing the test, the HPLC was rinsed by $10 \%$ methanol aqueous solution firstly to eliminate salts and then washed with pure methanol. The experimental design, data acquisition and data processing process shall comply with QA/QC requirements.

\section{RESULTS AND DISCUSSION}

\section{Growth Curve of Microcystis}

Growth curves of Microcystis under different culture conditions in the orthogonal test are shown in Fig. 1. Microcystis in 1\#, 2\#, 3\#, 4\# and 7\# begin the logarithmic growth on the $9^{\text {th }}$ day and the growth enters into the stable phase on the $27^{\text {th }}$ day. The growth of Microcystis in 5\# and 6\# enters into the logarithmic phase on the $5^{\text {th }}$ day. Microcystis in $5 \#$ and 6\# grows quickly and the number of algae cells reaches the peak on the $23^{\text {rd }}$ day. Microcystis in $8 \#$ and 9\# begin to grow logarithmically on the $7^{\text {th }}$ day and then the stable phase on the $25^{\text {th }}$ day. Meanwhile, Microcystis in 1\#, 4\# and 7\# under 200Lx illumination intensity grow slowly with the low algae biomass. This indicates that low illumination intensity can inhibit the growth of Microcystis significantly.

The specific growth rate and the maximum biomass of Microcystis at the logarithmic phase were further analyzed

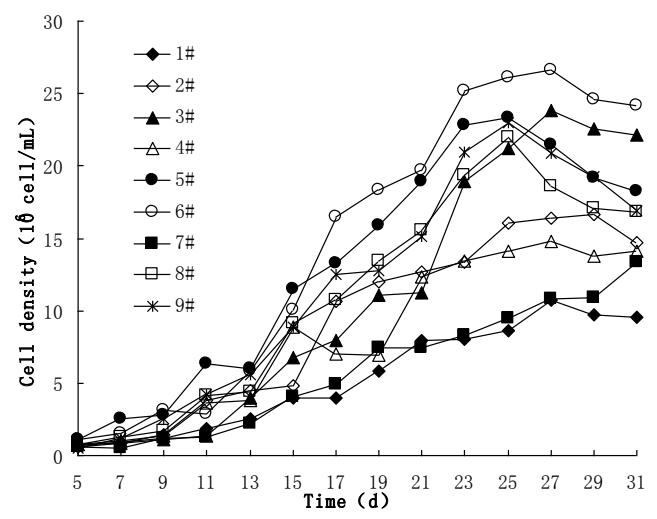

(1-9 \# are corresponding to those in Table 2)

Fig. 1: Variation curves of Microcystis density under different culture conditions.
Table 2: Comparison of growth rate and the maximum biomass of Microcystis under different culture conditions.

\begin{tabular}{|lll|}
\hline Number & $\begin{array}{l}\text { Compared growth rates } \\
\text { during logarithmic growth } / \mathrm{d}\end{array}$ & $\begin{array}{l}\text { Maximum biomass } \\
\left(10^{6} \mathrm{a} / \mathrm{mL}\right)\end{array}$ \\
\hline $1 \#$ & 0.123 & 10.75 \\
$2 \#$ & 0.137 & 16.65 \\
$3 \#$ & 0.170 & 23.8 \\
$4 \#$ & 0.133 & 14.8 \\
$5 \#$ & 0.167 & 23.35 \\
$6 \#$ & 0.176 & 26.6 \\
$7 \#$ & 0.124 & 13.375 \\
$8 \#$ & 0.158 & 21.975 \\
$9 \#$ & 0.164 & 22.95 \\
\hline
\end{tabular}

according to the growth curves under different culture conditions (Table 2). There is the largest biomass $\left(26.6 \times 10^{6} \%\right.$ $\mathrm{mL})$ in $6 \#$, which is followed by $3 \#\left(23.8 \times 10^{6} / \mathrm{mL}\right)$. The growth rates of Microcystis in 6\# and 3\# are 0.176 and 0.170 , respectively. The best growth of Microcystis was in 6\# in these treatments which might be from the compensation of different factors because it is supplied with lower nitrogen content and the longest illumination. The lowest maximum biomass $(10.75)$ and growth rate $(0.123)$ were in $1 \#$ due to the lowest temperature, nutrient salt content and short illumination. Moreover, there is a positive correlation between the maximum biomass and the growth rate in these treatments.

\section{Variation of MCs}

Effect of mutual orthogonality of temperature, illumination intensity, TN and TP on MCs is presented in Table 3. The contents of MCs increase continuously during the culture in all treatments. The MCs contents on the $23^{\text {rd }}$ day are highest for all treatments. Treatment group 4 achieves the highest MCs content on the $15^{\text {th }}$ day. The content of MCs increases quickly during the first 15 days and becomes stable subsequently. This might be caused by the short logarithmic phase of Microcystis in 4\#. The content of MCs on the $23^{\text {rd }}$ day is the highest among all treatments. The MCs content in 6\# was the highest, and the reason might be that there are the most algae cells in it. However, although the maximum biomass in $3 \#$ is next to that in 6\#, the content of MCs is only half of that in 6\#. This means that the content of MCs is not only related to biomass, but also other factors.

Synergy Effect of Temperature, Illumination Intensity, Nitrogen and Phosphorus on Biomass of Microcystis

To study the effect of degrees of temperature, illumination intensity, nitrogen and phosphorus on Microcystis growth, a statistical analysis on the biomass of Microcystis was con- 
Table 3: Content of MCs ( $\left.\mu \mathrm{g} . \mathrm{L}^{-1}\right)$ during 23-day culture.

\begin{tabular}{|llllll|}
\hline Number & $\begin{array}{l}\text { The } 7^{\text {th }} \\
\text { day }\end{array}$ & $\begin{array}{l}\text { The } 11^{\text {th }} \\
\text { day }\end{array}$ & $\begin{array}{l}\text { The } 15^{\text {th }} \\
\text { day }\end{array}$ & $\begin{array}{l}\text { The } 19^{\text {th }} \\
\text { day }\end{array}$ & $\begin{array}{l}\text { The } 23^{\text {rd }} \\
\text { day }\end{array}$ \\
\hline 1\# & 0.5240 & 1.7556 & 4.3031 & 18.0597 & 20.8622 \\
$2 \#$ & 0.1937 & 3.2324 & 5.8781 & 12.9239 & 21.9742 \\
$3 \#$ & 0.1588 & 2.7712 & 5.6402 & 10.0309 & 15.1562 \\
$4 \#$ & 0.1674 & 2.3533 & 27.4981 & 30.5777 & 31.5704 \\
$5 \#$ & 0.4844 & 2.8458 & 5.8047 & 10.9054 & 18.9009 \\
$6 \#$ & 0.2952 & 3.7680 & 14.0460 & 32.1244 & 46.3429 \\
$7 \#$ & 0.5303 & 2.0560 & 6.5060 & 10.3597 & 20.8562 \\
$8 \#$ & 0.2407 & 2.2880 & 10.8364 & 17.4097 & 18.2394 \\
9\# & 0.5552 & 2.2081 & 10.6787 & 13.5437 & 15.3474 \\
\hline
\end{tabular}

ducted. The orthogonal test was implemented according to Table 2. The absorbance value of algae solution was tested every other day since 7d, getting variation curves (Fig. 2). All treatment groups enter into the logarithmic phase since $9 \mathrm{~d}$ and have a long logarithmic phase. The maximum absorbance value of treatment group 6 is significantly higher than those of other treatment groups. The absorbance value of treatment group 1 changes slightly, but absorbance values of treatment group 2, 3, 4 and 7 vary similarly.

The relationship between the final optical density and specific growth rate during the growth of Microcystis is presented in Fig. 3. According to regression analysis, the correlation of specific growth rates of different treatment groups and their absorbance values is $y=7.3662 x-0.6187$ $\left(\mathrm{R}^{2}=0.9763\right.$. Therefore, the growth of Microcystis can be represented by the orthogonal analysis based on the final absorbance value.

Statistics were calculated according to the final absorbance values of Microcystis. The intuitive analysis results are listed in Table 4 . The mean value in Table 4 represents the average absorbance values of each level of different

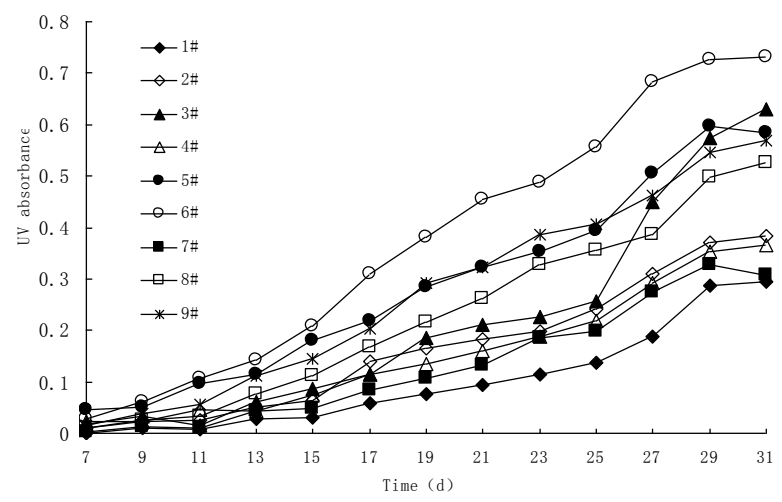

Fig. 2: Absorbance value of Microcystis under different culture conditions.

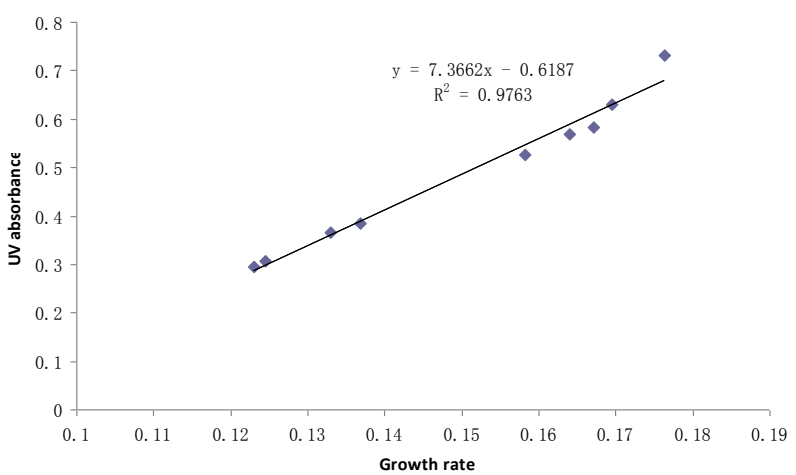

Fig. 3: Correlation between Microcystis absorbance and specific growth rate.

factors. For example, $\mathrm{T}_{11}, \mathrm{~T}_{21}$ and $\mathrm{T}_{31}$ represent the final absorbance values at $22^{\circ} \mathrm{C}, 25^{\circ} \mathrm{C}$ and $28^{\circ} \mathrm{C}$, respectively. It can be observed that Microcystis growth increases with the temperature rise, but the algal density begins to decrease after the temperature increases to a certain level. The content of Microcystis increases with the increase of illumination intensity. Microcystis growth changes similarly as TN and TP increases, decreasing first and then increasing. The range in Table 4 means the different effect of the factors on algae growth. The higher the range is, the stronger the effect was. As a result, illumination intensity influences the algal growth strongly, followed by temperature, TN and TP.

Illumination provides energies for the cellular metabolism of algae and affects algal growth and reproduction. Microcystis aeruginosa is known to respond to light availability with photoacclimation (Wyman et al. 1983). Huisman et al. (1999) reported that algal growth has specific "critical illumination intensity". For example, in the water column inoculated with Microcystis and Chlorella, Microcystis will be replaced by Chlorella gradually below 3,000Lx illumination intensity. However, in natural lakes and reservoirs, Microcystis could beat others in the light fight due to its strong buoyancy. When the controlled illumination intensity is lower than the "critical illumination intensity", algal biomass will decrease significantly. Our experiment also confirmed that very low illumination intensity will inhibit Microcystis growth. Microcystis aeruginosa is known for its resistance to photoinhibition and high light due to protective pigmentation (Paerl et al. 1983). The temperature has been shown to have a positive effect on the growth of M. aeruginosa (Rainer et al. 2016). Temperature affects algal growth directly or indirectly mainly by controlling physicochemical progress, such as the enzymatic reaction of photosynthesis, respiration intensity and decomposition of nutrient substances in water. In this study, it is discovered that algal content increases with the temperature rise, but algal density begins to decrease when 
Table 4: Visual analysis table about absorbance values of Microcystis.

\begin{tabular}{|llllll|}
\hline Number & \multicolumn{2}{l}{ Environmental factors } & & Absorbance values \\
\cline { 2 - 5 } & Temperature $\left({ }^{\circ} \mathrm{C}\right)$ & Light intensity $(\mathrm{Lx})$ & $\mathrm{TN}\left(\mathrm{mg} \cdot \mathrm{L}^{-1}\right)$ & $\mathrm{TP}\left(\mathrm{mg} . \mathrm{L}^{-1}\right)$ & \\
\hline 1 & 22 & 200 & 20 & 0.4 & 0.294 \\
2 & 22 & 500 & 60 & 0.6 & 0.384 \\
3 & 22 & 800 & 100 & 1.0 & 0.631 \\
4 & 25 & 200 & 60 & 1.0 & 0.366 \\
5 & 25 & 500 & 100 & 0.4 & 0.584 \\
6 & 25 & 800 & 20 & 0.6 & 0.7325 \\
7 & 28 & 200 & 100 & 0.6 & 0.3075 \\
8 & 28 & 500 & 20 & 1.0 & 0.5265 \\
9 & 28 & 800 & 60 & 0.4 & 0.568 \\
Mean value $\mathrm{T}_{1}$ & 0.436 & 0.322 & 0.518 & 0.482 & \\
Mean value $\mathrm{T}_{2}$ & 0.561 & 0.498 & 0.439 & 0.475 & \\
Mean value $\mathrm{T}_{3}$ & 0.467 & 0.644 & 0.507 & 0.508 & \\
Range & 0.125 & 0.322 & 0.079 & 0.033 & \\
\hline
\end{tabular}

the temperature increased to a certain level. Within the appropriate temperature range, cell activity enhances with the temperature rise. However, after the temperature reaches a certain level, algal metabolism accelerates, which requires more nutrients. Due to the decreasing nutrients in the water, algal cell death rate under high temperature is higher than the reproduction rate and algal growth is inhibited. Zhao et al. (2007) found that water temperature was an important factor in the shift of Microcystis and Oscillatoria dominance in a simulated, shallow, eutrophic lake. Algal reproduction is closely related to nitrogen and phosphorus concentrations in water (Stockner \& Shortreed 1988, Borchardt 1994). Tsukada et al. (2006) found that $\mathrm{P}$ limitation did not occur during the study period. The effect of $\mathrm{N}$ was stronger than that of $\mathrm{P}$ for blooms of Microcystis. The ratio of N/P plays an important role in Microcystis growth, and the low N/P ratio could be a consequence of the capacities and rates of uptake of nitrogen and phosphorus by cyanobacteria (Marinho \& Sandra 2007).

Synergy Effect of Temperature, Illumination Intensity, Nitrogen and Phosphorus on Toxin Production by Microcystis

In the experiment, a statistical analysis of MCs per unit cell was conducted on the 23rd day. Intuitive analysis results are

Table 5: Visual analysis table about single-cell toxin production by Microcystis.

\begin{tabular}{|c|c|c|c|c|c|}
\hline \multirow[t]{2}{*}{ Number } & \multicolumn{4}{|c|}{ Environmental factors } & \multirow{2}{*}{$\begin{array}{l}\text { Toxin production of single cell } \\
\left(\mathrm{fg} \cdot \mathrm{a}^{-1}\right)\end{array}$} \\
\hline & Temperature $\left({ }^{\circ} \mathrm{C}\right)$ & Light intensity (Lx) & $\mathrm{TN}\left(\mathrm{mg} \cdot \mathrm{L}^{-1}\right)$ & $\mathrm{TP}\left(\mathrm{mg} . \mathrm{L}^{-1}\right)$ & \\
\hline 1 & 22 & 200 & 20 & 0.4 & 2.5996 \\
\hline 2 & 22 & 500 & 60 & 0.6 & 1.6429 \\
\hline 3 & 22 & 800 & 100 & 1.0 & 0.8009 \\
\hline 4 & 25 & 200 & 60 & 1.0 & 2.3560 \\
\hline 5 & 25 & 500 & 100 & 0.4 & 0.8290 \\
\hline 6 & 25 & 800 & 20 & 0.6 & 1.8390 \\
\hline 7 & 28 & 200 & 100 & 0.6 & 2.5280 \\
\hline 8 & 28 & 500 & 20 & 1.0 & 0.9426 \\
\hline 9 & 28 & 800 & 60 & 0.4 & 0.7326 \\
\hline Mean value $T_{1}$ & 1.681 & 2.495 & 1.794 & 1.387 & \\
\hline Mean value $T_{2}$ & 1.675 & 1.138 & 1.577 & 2.003 & \\
\hline Mean value $T_{3}$ & 1.401 & 1.124 & 1.386 & 1.367 & \\
\hline Range & 0.280 & 1.371 & 0.408 & 0.636 & \\
\hline
\end{tabular}


listed in Table 5. The high MCs content per unit cell is in 1,4 and 7 \#, which indicated that low illumination intensity is beneficial for toxin production of Microcystis. Toxin production per unit cell of treatment group 9 is only next to that of treatment group 3, indicating that other factors could compensate for inadequate phosphorus to a certain extent. This reflects that there's mutual compensation among factors. Furthermore, illumination intensity affects the toxin production of Microcystis mostly, followed by TP, TN and water temperature.

In the experiment, levels of four factors are shown in the horizontal coordinate and their meaning is presented by the toxin production per unit cell at the vertical coordinate (Fig. 4). Four curves in Fig. 4 show the effect of temperature, illumination intensity, TN and TP on MCs content per unit cell of Microcystis. Effect of TP on toxin production per unit cell of Microcystis increases firstly and then decreases, indicating that there's an optimum P concentration within the selected range for Microcystis to produce MCs. In this experiment, it was concluded that $0.6 \mathrm{mg} . \mathrm{L}^{-1}$ is the optimum $\mathrm{P}$ concentration for the production of MCs. MCs content per unit cell of Microcystis increases with the decrease of illumination intensity. The effect of temperature and $\mathrm{TN}$ is similar to that of illumination intensity. In this study, the optimum illumination intensity, temperature and TN for Microcystis to produce toxin are $200 \mathrm{Lx}, 22^{\circ} \mathrm{C}$ and $20 \mathrm{mg} . \mathrm{L}^{-1}$, respectively.

According to the orthogonal test results, low illumination intensity could facilitate toxin production of Microcystis. This agrees with the research results of Rapala et al. (1997). Meanwhile, the effect of illumination intensity on toxin production is affected by temperature. With the increase of TP,
MCs show an inverse "V-shaped" variation. Low TP could accelerate MCs production. This echoes with many results (Vonshak et al. 1994, Christina \& Pedro 1994, Kameyama et al. 2002). The results of this study showed that there was a slight increase in MCs production at low temperature and a slight decrease in toxicity at high temperature, similar to the results from the studies of Watanabe \& Oishi (1985), Sivonen (1990) and Gilbert (1996). With limited phosphorus, both isomers of MCs and MCs increase. Nitrogen is an essential element for MCs synthesis. The proportion of nitrogen in MCs molecular structure was up to $14 \%$ (Botes et al. 1985). However, based on our orthogonal test results, $\mathrm{N}$ influences MCs slightly. Orr \& Jones (1998) found a linear relationship between cell division rate and total MCs production rate in Microcystis solution. MCs content per unit cell keeps constant during the cell cycle even though both total MCs content in algal solution and cell concentration increase with the increase of TN in culture medium. Therefore, it is speculated that the effect of TN on total MC may be insignificant because nitrogen changes total MCs content in Microcystis solution by influencing the algae cell growth, but there is no direct impact on MCs content per unit cell. Meanwhile, the orthogonal test results reveal that the optimum growth condition and the optimum toxin production condition of Microcystis are different from each other. Abundances of toxic strains of Microcystis have been specifically enhanced by additions of inorganic $\mathrm{N}$ (Davis et al. 2010).

\section{CONCLUSIONS}

Variation trends of Microcystis biomass and extracellular MCs are analyzed through a 29-day orthogonal test of tem-

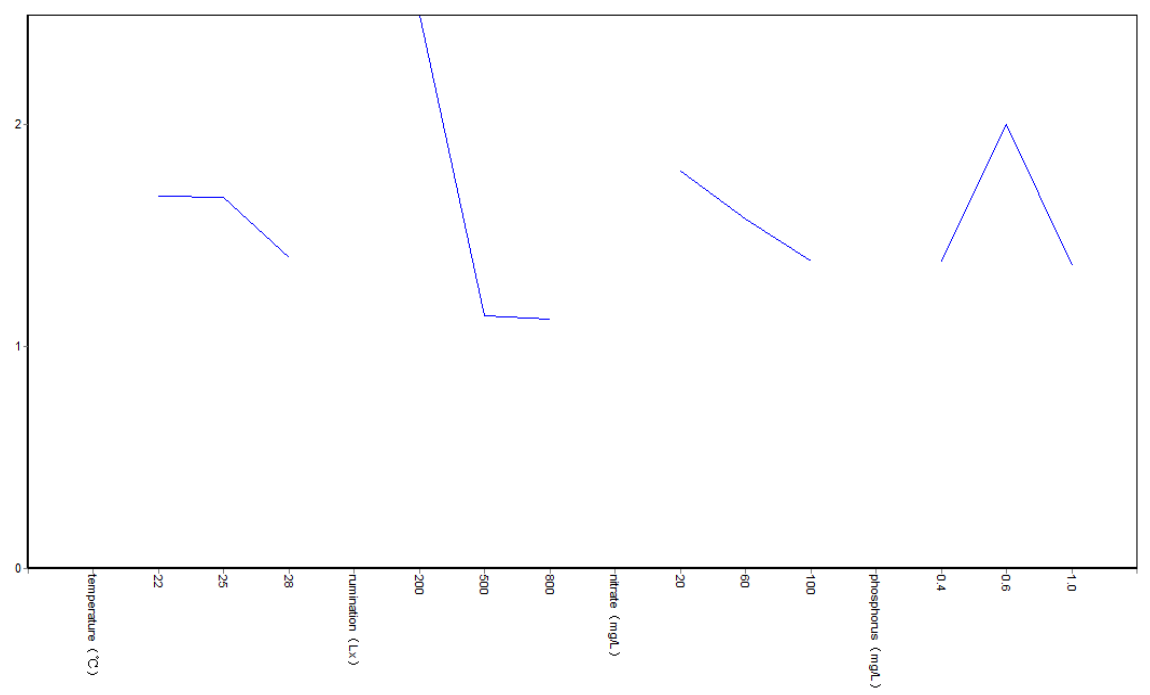

Fig. 4: Orthogonal test of temperature, illumination intensity, nitrogen and phosphorus. 
perature, illumination intensity, nitrogen and phosphorus. The conclusions are as following:

1. According to the intuitive analysis on optical density of Microcystis solution, illumination intensity influences Microcystis growth mostly, followed by temperature, TN and TP.

2. The MCs content in 6\# was the highest, and the reason might be that there are the most algal cells in it. However, although the maximum biomass in $3 \#$ is next to that in $6 \#$, the content of MCs is only half of that in $6 \#$. This means that the content of MCs is not only related to biomass, but also other factors

3. Illumination intensity influences toxin production of Microcystis strongly, followed by TP, TN and water temperature successively. With the increase of TP, MCs content per unit cell increases firstly and then decreases. In this study, the optimum TP for toxin production of Microcystis is $0.6 \mathrm{mg} . \mathrm{L}^{-1}$. Toxin production per unit cell is inversely proportional to illumination intensity, temperature and TN. The optimum illumination intensity, temperature and $\mathrm{TN}$ for toxin production of Microcystis are $200 \mathrm{Lx}, 22^{\circ} \mathrm{C}$ and $20 \mathrm{mg} . \mathrm{L}^{-1}$, respectively.

\section{ACKNOWLEDGEMENTS}

This research has been financed by the National Natural Science Foundation of China (31600311) and (31972522), the National Key Research and Development Project of China (2018YFC1801200), Major Science and Technology Project of Liaoning Province (2019JH1/10300001).

\section{REFERENCES}

Azevedo, S.M., Carmichael, W.W., Jochimsen, E.M., Rinehart, K.L., Lau, S., Shaw, G.R. and Eagleshan, G.K. 2002. Human intoxication by microcystins during renal dialysis treatment in Caruaru-Brazil. Toxicology, 181(24): 441-446.

Borchardt, M.A. 1994. Effects of flowing water on nitrogen-nitrogen and phosphorus limited photosynthesis and optimum N:P ratios by Spirogyra fluviatilis (Charophyceae). Journal of Phycology, 30(3): 418-430.

Botes, D.P., Wessels, P.L. and Kruger, H. 1985. Structural studies on cyanoginosins-LR, -YR, -YA and- YM, peptide toxins from Microcystis aeruginosa. Journal of the Chemical Society-Perkin Transactions, 1: 2747-2748

Christina, W.C. and Pedro, A.C. 1994. Factors influencing the development of Cylindrospermosis raciborskii and Microcystis aeruginosa in the Paranoa Reservoir, Brasilia, Brazil. Archive Fur Hydrobiologie Supplementband, 105: 85-96.

Davis, T.W., Harke, M.J., Marcoval, M.A., Goleski, J., Orano-Dawson, C., Berry, D. L. and Gobler, C.J. 2010. Effects of nitrogenous compounds and phosphorus on the growth of toxic and non-toxic strains of Microcystis during cyanobacterial blooms. Aquatic Microbial Ecology, 61(2): 149-162.

Downing, T.G., Sember, C.S., Gehringer, M.M. and Leukes, W. 2005. Medium N:P ratios and specific growth rate comodulate microcystin and protein content in Microcystis aeruginosa PCC7806 and M. aeruginosa UV027. Microbial Ecology, 49(3): 468-473.

Gilbert, J.J. 1996. Effect of temperature on the response of planktonic rotifers to a toxic cyanobacterium. Ecology, 77(4): 1174-1180.

Huisman, J., Jonker, R.R., Zonneveld, C. and Weissing, F.J. 1999. Competition for light between phytoplankton species: Experimental tests of mechanistic theory. Ecology, 80(1): 211-222.

Ingrid, C. and Jamie, B. 1999. Oxic Cyanobacteria in Water. London and New York. E\&FN Spon Publisher, 416-419.

Jähnichen, S., Long, B.M. and Petzoldt, T. 2011. Microcystin production by Microcystis aeruginosa: Direct regulation by multiple environmental factors. Harmful Algae, 12(4): 95-104.

Joung, S.H., Oh, H.M., Ko, S.R. and Ahn, C.Y. 2011. Correlations between environmental factors and toxic and non-toxic Microcystis dynamics during bloom in Daechung Reservoir, Korea. Harmful Algae, 10(2): 188-193.

Kameyama, K., Sugiura, N., Isoda, H., Inamori, Y. and Maekawa, T. 2002. Effect of nitrate and phosphate concentration on production of microcystins by Microcystis viridis NIES 102. Aquatic Ecosystem Health \& Management, 5(4): 443-449.

Lin, Y.Q., Chen, A.W., Luo, S., Kuang, X.L., Li, R.H., Lepo, J.E., Gu, J.D., Zeng, Q.R. and Shao, J.H. 2019. Cyanobacterial bloom mitigation by sanguinarine and its effects on aquatic microbial community structure. Environmental Pollution, 253: 497-506.

Liu, Y., Xie, P. and Wu, X.P. 2006. Effects of toxic and non-toxic Microcystis aeruginosa on survival, population-increase, and feeding of two small cladocerans. Bulletin of Environmental Contamination and Toxicology, 77: 566-573.

Margarita, M., Jorge, H. and Comin, F.A. 2002. Effect of nitrogen and phosphorus supply on growth, chlorophyll content and tissue composition of the macroalga Chaetomorpha linum (O. F. M üll.) Kütz in a Mediterranean coastal lagoon. Journal of Marine Science and Technology, 66: 355-364.

Marinho, M.M. and Sandra, M.F. 2007. Influence of N/P ratio on competitive abilities for nitrogen and phosphorus by Microcystis aeruginosa and Aulacoseira distans. Aquatic Ecology, 41(4): 525-533.

Oh, H.M., Lee, S.J., Jang, M.H. and Yoon, B.D. 2000. Microcystin production by Microcystis aeruginosa in a phosphorus-limited chemostat. Applied Environmental Microbiology, 66(1): 176-179.

Orr, P.T. and Jones G.J. 1998. Relationship between microcystin production and cell division rates in nitrogen-limited Microcystis aeruginosa cultures. Limnology \& Oceanography, 43(7): 1604-1614.

Paerl, H.W., Tucker, J. and Bland, P.T. 1983. Carotenoid enhancement and its role in maintaining blue-green algal (Microcystis aeruginosa) surface blooms. Limnology \& Oceanography, 28(5): 847-857.

Puschner, B., Galey, F.D., Johnson, B., Dickie, C.W. and Holstege, D.M. 1999. Blue-green algae toxicosis in cattle. Journal of the American Veterinary Medical Association, 213(11): 1605.

Rainer, K., Li, D. and Elisabeth, E. 2016. Role of toxic and bioactive secondary metabolites in colonization and bloom formation by filamentous cyanobacteria Planktothrix. Harmful Algae, 54: 69-86.

Rapala, J. 1998. Toxins production by freshwater cyanobacteria: Effects of environmental factors [Dissertation]. University of Helsinki.

Rapala, J., Sivonen, K., Lyra, C. and Niemelä, S.I. 1997. Variation of microcystins, cyanobacterial hepatotoxins, in Anabaena spp. as a function of growth stimuli. Appl. Environ. Microbiol., 63(6): 22062212 .

Reichwaldt, E.S. and Ghadouani, A. 2012. Effects of rainfall patterns on toxic cyanobacterial blooms in a changing climate: Between simplistic scenarios and complex dynamics. Water Research, 46(5): 1372-1393.

Sivonen, K. 1990. Effects of light, temperature, nitrate, orthophosphate, and bacteria on growth of and hepatotoxic production by Oscillatoria agardhii strains. Applied \& Environmental Microbiology, 56(9): 2658-2666. 
Stockner, J.G. and Shortreed, K.S. 1988. Response of Anabaena and Synechococcus to manipulation of nitrogen: Phosphorus ratios in a lake fertilization experiment. Limnology \& Oceanography, 33(6): 1348-1361.

Tilimanns, A., Wilson, A., Frances, R. and Sarnelle, O. 2008. Metaanalysis of cyanobacterial effects on zooplankton population growth rate: Species-specific responses. Fundamental \& Applied Limnology, 171(4): 285-295.

Tsukada, H., Tsujimura, S. and Nakahara, H. 2006. Effect of nutrient availability on the $\mathrm{C}, \mathrm{N}$, and $\mathrm{P}$ elemental ratios in the cyanobacterium Microcystis aeruginosa. Limnology, 7(3): 185-192.

Utkilen, H. and Gjølme, N. 1992. Toxin production by Microcystis aeruginosa as a function of light in continuous cultures and its ecological significance. Applied Environmental Microbiology, 58(4): 1321-5.

Van Apeldoorn, M.E., Van Egmond, H.P., Speijers, G.J. and Bakker, G.J. 2006. Toxins of cyanobacteria. Molecular Nutrition \& Food Research, 51(1): 7-60.
Vonshak, A., Torzillo, G. and Tomaseli, L. 1994. Use of chlorophyll fluorescence to estimate the effect of photoinhibition in outdoor cultures of Spirulina platensis. Journal of Applied Phycology, 6(1): 31-34.

WHO 1998. WHO Guidelines for Drinking Water Quality. Health criteria and other supporting information, 2: 95-110.

Watanabe, M.F. and Oishi, S. 1985. Effects of environmental factors on toxicity of a cyanobacterium (Microcystis aeruginosa) under culture conditions. Applied Environmental Microbiology, 49(5): 1342-1344.

Wiedner, C., Visser, P.M., Fastner, J., Metcalf, J.S., Codd, G.A. and Mur, L.R. 2003. Effects of light on the microcystin content of Microcystis strain PCC 7806. Applied Environmental Microbiology, 69(3): 1475.

Wyman, K., Siegelman, H.W. and Falkowski, P.G. 1983. Adaptation of the cyanobacterium Microcystis aeruginosa to light intensity. Plant Physiology, 72(3): 829-832.

Zhaosheng, C., Xiangcan, J., Norio, I. and Yuhei, I. 2007. The effect of temperature on growth characteristics and competitions of Microcystis aeruginosa and Oscillatoria mougeotii in a shallow, eutrophic lake simulator system. Hydrobiologia, 581: 217-223. 